Research Article

\title{
A New Green Efficiency-Based Carbon Taxing Policy and Its Effects on a Production-Inventory System with Random Carbon Emissions and Green Investment
}

\author{
Tapan Kumar Datta $(\mathbb{D}$ \\ BITS Pilani, Dubai Campus, Dubai International Academic City, P.O. Box 345055, Dubai, UAE \\ Correspondence should be addressed to Tapan Kumar Datta; dutta@dubai.bits-pilani.ac.in
}

Received 28 July 2020; Revised 9 October 2020; Accepted 16 October 2020; Published 29 October 2020

Academic Editor: Yi-Kuei Lin

Copyright ( 2020 Tapan Kumar Datta. This is an open access article distributed under the Creative Commons Attribution License, which permits unrestricted use, distribution, and reproduction in any medium, provided the original work is properly cited.

\begin{abstract}
In this study, the author proposes a new carbon taxing policy. This proposed carbon tax has two tax components. The first component is constant, and the second component depends on the green efficiency of production. The green efficiency of production is measured by the average amount of emissions per unit production in an assessment year. The green efficiency-based tax component can be reset every year. Lesser average emission rate indicates better green efficiency. The second component of this proposed carbon tax forces the firm to improve the green efficiency of production, which results in cleaner production. The author incorporates this new carbon tax policy in a production-inventory system with a price-sensitive demand rate. A rule is provided for the implementation of this new tax. Emissions during setup, production, and storage are considered as independent random variables. The firm has the opportunity of investing in green technologies to improve green efficiency. A profit maximization policy is adopted to solve the developed model. A solution algorithm is also provided. The model is illustrated by numerical examples with randomly generated model parameters. The results of numerical examples show the environmental benefits of the proposed carbon tax.
\end{abstract}

\section{Introduction}

Over the past decades, global warming has received growing attention worldwide. It poses a serious threat to our planet because its consequences are devastating, far-reaching, and long-lasting. Global warming gradually damages our planet's ecosystem, which results in the extinction of many plant and animal species. Rise of sea level, depletion of the ozone layer, increase in average, earth's temperature, extreme weather conditions, frequent and intense storm, drought, flood, and increased clear-air turbulence are some of the catastrophic effects of global warming (https://www. carbonpricingleadership.org/who/ $[1,2])$. Industrialization, urbanization, transportation, and electricity generation are some human activities, which emit a huge amount of GHGs because these activities need to burn fossil fuels. The Intergovernmental Panel on Climate Change (IPCC), which includes more than 1,300 scientists from the United States and other countries, forecasts a temperature rise of 2.5 to 10 degrees Fahrenheit over the next century (https://climate. nasa.gov/effects/). Tollefson [3] predicted, "two degrees of warming could destroy ecosystems on around $13 \%$ of the world's land area, increasing the risk of extinction for many insects, plants, and animals. Holding warming to $1.5^{\circ} \mathrm{C}$ would reduce that risk by half." There is a growing consensus that carbon emissions are a leading contributor to global warming [4]. The industrial sector is one of the major contributors of GHGs emissions. In 2014, the United States (US) Environmental Protection Agency (EPA) reported that industry was the third major contributor to GHG emissions, contributing $21 \%$ of the total GHG emissions in the US. The industrial process consists of production/manufacturing, transportation, storage, waste disposal, etc. Each of these activities emits a huge amount of GHGs. The amount of 
emissions varies from industry to industry. The growing environmental consciousness of the users of the end products compels the manufacturers to tend towards green products. In a manufacturing system, three main phases of emissions are: production setup/order placing, production process, and storage [1,4]. Emission rates in these three sources are different. Efficient production and inventory control, wise managerial decisions, green technology implementation, and environmental awareness can considerably reduce carbon emissions during manufacturing activities [1]. Strict environmental legislation is also essential to mitigate emissions. Regulatory bodies of many developed and developing countries are enacting carbon policies to reduce emissions. Carbon tax and emission trading systems (also known as cap-and-trade) are the most common mechanisms implemented in many countries to mitigate emissions. Many countries adopted a carbon tax policy to reduce carbon emissions and promote energy saving. Chile, Colombia, Finland, Argentina, Sweden, Switzerland, Netherland, Norway, Alberta, UK, and Italy are some countries/states who implemented a carbon tax. Environmental legislation affects the optimal inventory decision and must be incorporated in designing a sustainable inventory model [5]. There is a growing interest among many researchers to include environmental parameters in designing their models. A number of research papers are available in the existing literature which includes sustainability in the production-inventory system and supply chain [5-28]. García-Alvarado et al. [18] analyzed a stochastic closed-loop inventory model with environmental constraints. They adopted a discrete-in-time periodic review policy with a finite horizon. Battini et al. [16] incorporated sustainability in a single product replenishment problem under the traditional economic order quantity (EOQ) framework. Glock et al. [11] developed an inventory model with price- and quality-sensitive demand. They considered a single product with sustainability as a quality attribute and measured in terms of the level of scraps and emission in the supply chain. Zanoni et al. [26] published a research article on the joint economic lot size model with price and environmentally sensitive demand in a vendor-buyer supply chain. Absi et al. $[6,12]$ developed single item, multisourcing, and carbonconstrained lot size models. Hovelaque and Bironneau [21] investigated an inventory system with price and emissiondependent demand under environmental conditions. They showed the environmental benefit of a carbon tax. He et al. [22] investigated the production lot-sizing issues of a firm under a carbon tax and cap-and-trade regulations. Dye and Yang [5] and Tsao et al. [25] developed sustainable inventory models with trade credit under various environmental regulations. It is important to note that none of these studies included green investment as one of the model parameters. A firm should invest money on green technologies for cleaner production that also reduces the burden of the carbon tax. The green investment amount is an important decision parameter, and it should be included as a model parameter, while developing a sustainable model. Some researchers realized this fact and considered the green investment as a model parameter in their models. Jiang and Klabjan [29] investigated a joint production capacity and green investment decision policy under command-andcontrol and market-based regulations for an emission intensive company with stochastic demand. Lou et al. [30] incorporated green technology investment as a model parameter in a supply chain model to analyze the consequences of emission trading policy. Toptal et al. [31] analyzed a retailer's joint decision policy on inventory replenishment and green investment with emission regulation policies. $\mathrm{Bi}$ et al. [32] studied on governmental subsidy policy to motivate firms' adoption of green investment when consumers are environmentally discerning. Datta [1] published a research article on a production-inventory system with defective product under a carbon tax and green investment. Zheng et al. [33] considered green technology investment in a duopoly manufacturers' game model under the cap-andtrade policy. Recently, Datta et al. [34] published a research article with a hybrid carbon tax and emission source-based green investment. None of the above studies considered random emissions. In the real world, the amount of GHGs emitted by a firm to produce each unit of the product is not exactly the same, varies randomly. Hence, the inclusion of random emissions in a sustainable model will make the model more realistic, particularly when the emissions rate is more volatile.

In the present article, the author proposes a novel carbon taxing policy. This proposed carbon tax consists of a constant tax component and another component based on green efficiency of production. We analyze the effects of this taxing policy on the optimal decisions in the production and inventory system of a manufacturing firm. The green efficiency of production is measured by the average emission per unit production in an assessment year. This new carbon tax can be highly effective if applied to large firms, which are the main polluters. It guarantees cleaner production. In this paper, the proposed carbon tax will be termed as green efficiency-based (GE-based) carbon tax. The model considers independent random emissions released from three main emission sources (setup, production process, and warehouse/stock-holding) of the production system. The model also incorporates green investment as a decision parameter. The demand rate is assumed to be price sensitive. To solve the model, the author adopts a profit maximization policy with the selling price, green investment, and production run-time as decision parameters. To the best of the author's knowledge, none of the existing published articles focuses on random emissions and green efficiency-based carbon tax system. The author provides a solution algorithm. Five randomly generated numerical problems are solved to illustrate the model. To justify the contribution of this study, a comparison of this study with some related published works is shown in Table 1. The rest of the paper is organized as follows. Section 2 describes the assumptions and notations used in the model. Sections 3 and 4, respectively, present the model development and the solution algorithm. 
TABLE 1: Comparison of the present study with other related studies.

\begin{tabular}{|c|c|c|c|c|c|}
\hline Studies & Model type & $\begin{array}{l}\text { Random } \\
\text { emissions? }\end{array}$ & $\begin{array}{c}\text { GE-based } \\
\text { carbon tax? }\end{array}$ & Demand rate & $\begin{array}{c}\text { Green } \\
\text { investment? }\end{array}$ \\
\hline Aliabadi et al. [14] & Inventory & No & No & $\begin{array}{c}\text { Credit period, price, and emission } \\
\text { dependent }\end{array}$ & No \\
\hline Arslan and Turkay [7] & EOQ model & No & No & Constant & No \\
\hline Battini et al. [16] & EOQ model & No & No & Constant & No \\
\hline Chen et al. [10] & EOQ model & No & No & Constant & No \\
\hline Datta [1] & Production-inventory & No & No & Price-dependent & Yes \\
\hline $\begin{array}{l}\text { Gautam and } \\
\text { Khannna [19] }\end{array}$ & Inventory in supply chain & No & No & Constant & No \\
\hline Hammami et al. [20] & Production-inventory & No & No & Finite and constrained & No \\
\hline $\begin{array}{l}\text { Jiang and Klabjan } \\
\text { [29] }\end{array}$ & Production model & No & No & Stochastic & Yes \\
\hline Konur et al. [4] & $\begin{array}{l}\text { Inventory control (multi- } \\
\text { echelon) }\end{array}$ & $\begin{array}{l}\text { Randomly } \\
\text { generated }\end{array}$ & No & Stochastic & No \\
\hline Lin and Sarker [23] & Inventory & No & No & Constant & No \\
\hline Toptal et al. [31] & Inventory model & No & No & Constant & Yes \\
\hline Datta et al. [34] & Production-inventory & No & No & Price-dependent & Yes \\
\hline This study & Production-inventory & Yes & Yes & Price-dependent & Yes \\
\hline
\end{tabular}

In Section 5, the author proposes how this proposed carbon tax can be implemented. Numerical illustrations are presented in Section 6. Section 7 shows the environmental benefits of the proposed carbon tax. Section 8 performs an analysis to observe the effects of the new green efficiencybased tax component on the optimum solutions. In Section 9 , the author presents concluding remarks and future scopes.

\section{Assumptions and Notations}

(i) Time horizon is infinite.

(ii) Shortages are not permitted.

(iii) The product is nondeteriorating.

(iv) Emissions during setup, production, and holding (storage) are independent random variables.

(v) Demand rate is a decreasing linear function of selling price.

(vi) Carbon tax per unit emissions has two tax components: one tax component is constant and the other component depends on the green efficiency of production.

$P$ : production rate, which is known and constant (in units/year).

$\tau$ : production run-time (in year).

$T$ : length of a production cycle (in year).

$s$ : selling price of each unit (in $\$$ ), $s>0$.

$D$ : the demand rate (in units/year). The demand rate is a decreasing function of $s$. We take it as $D=\alpha-\beta s$, where $\alpha, \beta>0$ and $s<(\alpha / \beta)$.

$C_{u}$ : unit cost (in \$).

$C_{h}$ : carrying cost per unit per year (in \$).

$C_{s}$ : setup cost per production cycle (in $\$$ ). $e_{1}$ : total emissions for setup activities, a random variable (in ton).

$e_{2}$ : emissions per unit production run-time due to machining operations, a random variable (in ton).

$e_{3}$ : emissions per unit per year for holding inventory, a random variable (in ton).

$f_{i}\left(e_{i}\right)$ : probability density function of $e_{i}$ defined in $\left[0, R_{i}\right]$. The joint density function of $e_{1}, e_{2}$, and $e_{3}$ is $f\left(e_{1}, e_{2}, e_{3}\right)=f_{1}\left(e_{1}\right) \cdot f_{2}\left(e_{2}\right) \cdot f_{3}\left(e_{3}\right) \quad$ because $e_{1}, e_{2}$, and $e_{3}$ are independent random variables.

$\mu_{i}$ : the expected value of $e_{i}$ defined by $\mu_{i}=\int_{0}^{R_{i}} e_{i} f_{i}\left(e_{i}\right) \mathrm{d} e_{i}, i=1,2,3$.

$\sigma_{i}^{2}$ : the variance of $e_{i}$ defined by $\sigma_{i}^{2}=\int_{0}^{R_{i}} e_{i}^{2} f_{i}\left(e_{i}\right) \mathrm{d} e_{i}-\mu_{i}^{2}, i=1,2,3$.

$E_{T}$ : total emissions during a production cycle (in ton).

$E_{A}$ : average emissions per year during a production cycle (in ton).

$G(>0)$ : index representing the green efficiency of production (in ton/unit). This index is the average amount of emissions per unit production. A smaller value of index $G$ indicates cleaner production.

$C_{t}$ : carbon tax per unit emission (in \$). This carbon tax is the proposed carbon tax, an increasing function of green efficiency index " $G$." We take it in the form $C_{t}=a+b G, a, b \geq 0$ where $G=E_{T} / P \tau$.

APR: average profit per year in a production cycle (in \$).

$\mathrm{EAP}: \mathrm{EAP}=E(\mathrm{APR})$, expected average profit per year in a production cycle (in $\$$ ).

$I$ : total $\$$ investment in green technology. This investment is a one-off investment. The green 
investment $\$ I$ reduce the total emissions to a proportion of $e^{-\lambda I}$.

$I_{\max }:$ cap/budget on green investment (in \$).

$(\cdot)^{*}:(\cdot)$ is at optimum.

\section{The Model Development}

We assume that the firm starts its production after all necessary green installations. The production starts at time $t=0$ and continues until time $t=\tau$. During production runtime $[0, \tau]$, the inventory level accumulates at the rate of $(P-D(s))$ per year and reaches the maximum level at time $t=\tau$. During the period $[\tau, T]$, the inventory level depletes at the rate of $D(s)$ per year and becomes zero at time $t=T$. The cycle length is $T$ years. Let us now calculate the average emissions per year in a production cycle. is

Total emission in a production cycle without investment

$$
E_{T}=e_{1}+e_{2} \tau+e_{3}(P-D) \tau \frac{T}{2}
$$

Using the relation $T=(P \tau / D)$, we obtain

$$
E_{T}=e_{1}+e_{2} \tau+\frac{e_{3}(P-D) P \tau^{2}}{2 D} .
$$

With the green investment, it becomes $E_{T} e^{-\lambda I}$.

The average emission per unit time without investment is $E_{A}=E_{T} / T$, and with the green investment, it becomes $E_{A} e^{-\lambda I}$.
The index representing the green efficiency of production is defined by

$$
G=\frac{E_{T} e^{-\lambda I}}{P \tau} .
$$

Costs, revenue, and the average profit per year during the cycle $[0, T]$ :

$$
\begin{aligned}
\text { setup cost } & =C_{s}, \\
\text { unit cost } & =C_{u} P \tau, \\
\text { holding cost } & =\left(\frac{C_{h}}{2}\right)(P-D) \tau T, \\
\text { green investment } & =I, \\
\text { carbon tax } & =C_{t} E_{T} e^{-\lambda I} \\
& =\left(a+b \frac{E_{T} e^{-\lambda I}}{P \tau}\right) E_{T} e^{-\lambda I} \\
& =a e^{-\lambda I} E_{T}+\frac{b e^{-2 \lambda I}}{P \tau} E_{T}^{2} .
\end{aligned}
$$

Total revenue by selling the goods $=P \tau$ s.

The average profit per year in a production cycle is

$$
\mathrm{APR}=\frac{1}{T}(\text { total income }- \text { setup cost }- \text { unit cost }- \text { holding cost }- \text { green investment }- \text { carbon tax })
$$

Using the relation $T=(P \tau / D)$, we obtain

$$
\operatorname{APR}(\tau, s, I)=\left(\left(s-C_{u}\right) D(s)\right)-\left\{\begin{array}{c}
\frac{\left(C_{s}+I\right) D(s)}{P \tau}+\frac{C_{h} \tau}{2}(P-D(s))+\frac{a D(s) e^{-\lambda I}}{P}\left(\frac{e_{1}}{\tau}+e_{2}+\frac{e_{3} P \tau(P-D(s))}{2 D(s)}\right) \\
+\frac{b D(s) e^{-2 \lambda I}}{P^{2}}
\end{array}\right\}
$$

Because of the presence of three random variables $e_{1}, e_{2}$, and $e_{3}$ in $\mathrm{APR}$, we require to maximize the expected average profit $\operatorname{EAP}(\tau, s, I)$, defined by 


$$
\begin{aligned}
& \operatorname{EAP}(\tau, s, I)=E(\mathrm{APR})= \int_{0}^{R_{3}} \int_{0}^{R_{2}} \int_{0}^{R_{1}} \mathrm{APR} \cdot f\left(e_{1}, e_{2}, e_{3}\right) \mathrm{d} e_{1} \mathrm{~d} e_{2} \mathrm{~d} e_{3}, \\
&= \int_{0}^{R_{3}} \int_{0}^{R_{2}} \int_{0}^{R_{1}} \mathrm{APR} \cdot f\left(e_{1}\right) \cdot f\left(e_{2}\right) \cdot f\left(e_{3}\right) \mathrm{d} e_{1} \mathrm{~d} e_{2} \mathrm{~d} e_{3} \\
&=\left(\left(s-C_{u}\right) D(s)\right)-\frac{\left(C_{s}+I\right) D(s)}{P \tau}-\frac{C_{h} \tau}{2}(P-D(s)) \\
&-\frac{a D(s) e^{-\lambda I}}{P}\left(\frac{\int_{0}^{R_{1}} e_{1} f\left(e_{1}\right) \mathrm{d} e_{1}}{\tau}+\int_{0}^{R_{2}} e_{2} f\left(e_{2}\right) \mathrm{d} e_{2}+\frac{\int_{0}^{R_{3}} e_{3} f\left(e_{3}\right) \mathrm{d} e_{3} P \tau(P-D(s))}{2 D(s)}\right) \\
&-\frac{\int_{0}^{R_{1}} e_{1}^{2} f\left(e_{1}\right) \mathrm{d} e_{1}}{\tau^{2}}+\int_{0}^{R_{2}} e_{2}^{2} f\left(e_{2}\right) \mathrm{d} e_{2}+\frac{P^{2} \tau^{2}(P-D(s))^{2} \int_{0}^{R_{3}} e_{3}^{2} f\left(e_{3}\right) \mathrm{d} e_{3}}{P^{2}} \\
&\left(\begin{array} { c } 
{ 2 \lambda ( s ) \} ^ { 2 } } \\
{ + \int _ { 0 } ^ { R _ { 1 } } e _ { 1 } f ( e _ { 1 } ) \mathrm { d } e _ { 1 } \cdot \int _ { 0 } ^ { R _ { 2 } } e _ { 2 } f ( e _ { 2 } ) \mathrm { d } e _ { 2 } } \\
{ \tau }
\end{array} \left(\frac{P(P-D(s)) \int_{0}^{R_{1}} e_{1} f\left(e_{1}\right) \mathrm{d} e_{1} \cdot \int_{0}^{R_{3}} e_{3} f\left(e_{3}\right) \mathrm{d} e_{3}}{D(s)}\right.\right. \\
&+\frac{P \tau(P-D(s)) \int_{0}^{R_{2}} e_{2} f\left(e_{2}\right) \mathrm{d} e_{2} \cdot \int_{0}^{R_{3}} e_{3} f\left(e_{3}\right) \mathrm{d} e_{3}}{D(s)}
\end{aligned}
$$

On simplifying, we obtain

$\operatorname{EAP}(\tau, s, I)=E(\mathrm{APR})$

$$
=\left(\left(s-C_{u}\right) D(s)\right)-\left\{\begin{array}{c}
\frac{\left(C_{s}+I\right) D(s)}{P \tau}+\frac{C_{h} \tau}{2}(P-D(s))+\frac{a D(s) e^{-\lambda I}}{P}\left(\frac{\mu_{1}}{\tau}+\mu_{2}+\frac{\mu_{3} P \tau(P-D(s))}{2 D(s)}\right) \\
+\frac{b D(s) e^{-2 \lambda I}}{P^{2}}\left(\begin{array}{c}
\frac{\sigma_{1}^{2}+\mu_{1}^{2}}{\tau^{2}}+\left(\sigma_{2}^{2}+\mu_{2}^{2}\right)+\frac{\left(\sigma_{3}^{2}+\mu_{3}^{2}\right) P^{2} \tau^{2}(P-D(s))^{2}}{4\{D(s)\}^{2}} \\
+\frac{2 \mu_{1} \mu_{2}}{\tau}+\frac{\mu_{1} \mu_{3} P(P-D(s))}{D(s)}+\frac{\mu_{2} \mu_{3} P \tau(P-D(s))}{D(s)}
\end{array}\right.
\end{array}\right\} .
$$

The following optimization problem represents the proposed system:

$$
\begin{array}{ll}
\text { maximize } & \operatorname{EAP}(\tau, s, I) \\
\text { subject to } & \tau>0,0<s<\frac{\alpha}{\beta}, 0 \leq I \leq I_{\max } .
\end{array}
$$

Let us express EAP in powers of $\tau$ as follows:

$$
\mathrm{EAP}=X_{1} \tau^{2}+X_{2} \tau+X_{3}+\frac{X_{4}}{\tau}+\frac{X_{5}}{\tau^{2}},
$$

(9) where

$$
\begin{aligned}
& X_{1}=-\frac{e^{-2 \lambda I} b\left(\sigma_{3}^{2}+\mu_{3}^{2}\right)\{P-D(s)\}^{2}}{4 D(s)}, \\
& X_{2}=-\left\{\frac{\left(e^{-\lambda I} a \mu_{3}+C_{h}\right)}{2}+\frac{e^{-2 \lambda I} b \mu_{2} \mu_{3}}{P}\right\}\{P-D(s)\},
\end{aligned}
$$




$$
\begin{aligned}
& X_{3}=\left(s-C_{u}\right) D(s)-\frac{e^{-\lambda I} a D(s) \mu_{2}}{P}-\frac{e^{-2 \lambda I} b D(s)\left(\sigma_{2}^{2}+\mu_{2}^{2}\right)}{P^{2}}-\frac{e^{-2 \lambda I} b \mu_{1} \mu_{3}\{P-D(s)\}}{P}, \\
& X_{4}=-\left\{\frac{\left(C_{s}+I+e^{-\lambda I} a \mu_{1}\right) D(s)}{P}+\frac{2 e^{-2 \lambda I} b \mu_{1} \mu_{2} D(s)}{P^{2}}\right\}, \\
& X_{5}=-\frac{e^{-2 \lambda I} b\left(\sigma_{1}^{2}+\mu_{1}^{2}\right) D(s)}{P^{2}} .
\end{aligned}
$$

One can observe that $X_{1}, X_{2}, X_{4}, X_{5}<0$.

In the above equation, $X_{1}, X_{2}, X_{3}, X_{4}$, and $X_{5}$ are functions of the decision variables $s$ and $I$.

The following are two important properties derived from the structural characteristics of EAP.

Property 1. For fixed $s$ and $I$, the expected average profit EAP is concave in $\tau$, and it attains its maximum value in the interval:

$$
\tau \in\left(0, \max \left\{\left(\frac{X_{4}}{2 X_{1}}\right)^{(1 / 3)},\left(\frac{2 X_{5}}{X_{2}}\right)^{(1 / 3)}\right\}\right)
$$

Proof. To prove the concavity of EAP in $\tau$, we need to show that $\left(\partial^{2} \mathrm{EAP} / \partial \tau^{2}\right)<0$.

For fixed $s$ and $I$, the expressions $X_{1}, X_{2}, X_{3}, X_{4}$, and $X_{5}$ become constant, and so EAP depends on $\tau$ only. Now, differentiating EAP twice successively with respect to $\tau$, we obtain

$$
\begin{aligned}
\frac{\partial \mathrm{EAP}}{\partial \tau} & =2 X_{1} \tau+X_{2}-\frac{X_{4}}{\tau^{2}}-\frac{2 X_{5}}{\tau^{3}}, \\
\frac{\partial^{2}(\mathrm{EAP})}{\partial \tau^{2}} & =2 X_{1}+\frac{2 X_{4}}{\tau^{3}}+\frac{6 X_{5}}{\tau^{4}} .
\end{aligned}
$$

We obtain $\left(\partial^{2}(\mathrm{EAP}) / \partial \tau^{2}\right)<0$ because $X_{1}, X_{4}, X_{5}<0$ and $\tau>0$. This proves the concavity of EAP in $\tau$.

The value of $\tau$, which maximizes EAP, is the positive root of $(\partial(\mathrm{EAP}) / \partial \tau)=0$

Now, $(\partial(\mathrm{EAP}) / \partial \tau)=0$

$$
\begin{aligned}
& \Longrightarrow 2 X_{1} \tau+X_{2}-\frac{X_{4}}{\tau^{2}}-\frac{2 X_{5}}{\tau^{3}}=0, \\
& \Longrightarrow L(\tau)=0,
\end{aligned}
$$

where $L(\tau)=2 X_{1} \tau^{4}+X_{2} \tau^{3}-X_{4} \tau-2 X_{5}$

For any fixed values of $s$ and $I$, equation (14) is a polynomial equation in $\tau$ of degree 4 with constant coefficients. We observe that there is only one change in sign in the polynomial $L(\tau)$. So, by Descartes' rule of sign, the polynomial equation (14) has at most one positive root. We further observe that $L(0)=-2 X_{5}>0$ and $L(\tau) \longrightarrow$ $-\infty(<0)$ as $\tau \longrightarrow \infty$. Therefore, by the property of polynomial equations, the equation (14) has an odd number of positive roots. Combining these results, we conclude that the equation (14) has a unique positive root. This positive root maximizes EAP because EAP is concave in $\tau$.

Let us now prove that the positive root of the polynomial equation (14) lies in the open interval

$$
\left(0, \max \left\{\left(\frac{X_{4}}{2 X_{1}}\right)^{(1 / 3)},\left(\frac{2 X_{5}}{X_{2}}\right)^{(1 / 3)}\right\}\right) \text {. }
$$

We obtain

$$
\begin{aligned}
L(\tau) & =2 X_{1} \tau^{4}+X_{2} \tau^{3}-X_{4} \tau-2 X_{5} \\
& =\tau\left(2 X_{1} \tau^{3}-X_{4}\right)+\left(X_{2} \tau^{3}-2 X_{5}\right),
\end{aligned}
$$

$\tau>\left(\frac{X_{4}}{2 X_{1}}\right)^{(1 / 3)} \Longrightarrow \tau^{3}>\frac{X_{4}}{2 X_{1}} \Longrightarrow 2 X_{1} \tau^{3}-X_{4}<0, \quad \because X_{1}<0$ $\tau>\left(\frac{2 X_{5}}{X_{2}}\right)^{(1 / 3)} \Longrightarrow \tau^{3}>\frac{2 X_{5}}{X_{2}} \Longrightarrow X_{2} \tau^{3}-2 X_{5}<0, \quad \because X_{2}<0$.

So, $L(\tau)<0$ for $\tau>\max \left\{\left(X_{4} /\left(2 X_{1}\right)\right)^{(1 / 3)},\left(\left(2 X_{5}\right) /\right.\right.$ $\left.\left.X_{2}\right)^{(1 / 3)}\right\}$. But, $L(0)=-2 X_{5}>0$.

Hence, the positive root lies in the open interval $\left(0, \max \left\{\left(X_{4} /\left(2 X_{1}\right)\right)^{(1 / 3)},\left(\left(2 X_{5}\right) / X_{2}\right)^{(1 / 3)}\right\}\right)$.

We complete the proof of Property 1 .

Property 2. For fixed $s$ and $\tau$, the function EAP is concave in green investment $I$.

We obtain

$$
\frac{\partial(\mathrm{EAP})}{\partial I}=-Y_{1}+Y_{2} e^{-\lambda I}+Y_{3} e^{-2 \lambda I}
$$

where 


$$
\begin{aligned}
& Y_{1}=\frac{D(s)}{P \tau}>0, \\
& Y_{2}=a \lambda\left(\frac{\mu_{1} D(s)}{P \tau}+\frac{\mu_{2} D(s)}{P}+\frac{\mu_{3}(P-D(s)) \tau}{2}\right)>0, \\
& Y_{3}=b \lambda\left(\begin{array}{c}
\frac{\left(\sigma_{3}^{2}+\mu_{3}^{2}\right) \tau^{2}\{P-D(s)\}^{2}}{2 D(s)}+\frac{2 \mu_{2} \mu_{3} \tau\{P-D(s)\}}{P}+\frac{2\left(\sigma_{2}^{2}+\mu_{2}^{2}\right) D(s)}{P^{2}} \\
+\frac{2 \mu_{1} \mu_{3}\{P-D(s)\}}{P}+\frac{4 \mu_{1} \mu_{2} D(s)}{P^{2} \tau}+\frac{2\left(\sigma_{1}^{2}+\mu_{1}^{2}\right) D(s)}{P^{2} \tau^{2}}
\end{array}\right)>0 .
\end{aligned}
$$

We observe that $Y_{1}, Y_{2}$, and $Y_{3}$ are functions of $s$ and $\tau$. For any fixed values of $s$ and $\tau$, the values of $Y_{1}, Y_{2}$, and $Y_{3}$ are constant.

Now, $\quad\left(\partial^{2}(\mathrm{EAP}) / \partial I^{2}\right)=-\lambda Y_{2} e^{-\lambda I}-2 \lambda Y_{3} e^{-2 \lambda I}<0 \quad$ because $\lambda, Y_{2}, Y_{3}>0$. Hence, EAP is concave in $I$. This completes the proof of Property 2 .

Let us now find a decision rule to find the optimum value $I^{*}$ of the green investment $I$ for any fixed values of $s$ and $\tau$. We have already proved the concavity of EAP in $I$ for fixed values of $s$ and $\tau$. Therefore, the optimum value of $I$ can be obtained by solving the equation $\partial(\mathrm{EAP}) / \partial I=0$.

Now

$$
\begin{aligned}
\frac{\partial(\mathrm{EAP})}{\partial I} & =0 \\
& \Longrightarrow-Y_{1}+Y_{2} e^{-\lambda I}+Y_{3} e^{-2 \lambda I}=0, \\
& \Longrightarrow Y_{1} Z^{2}-Y_{2} Z-Y_{3}=0,
\end{aligned}
$$

where $Z=e^{\lambda I}$.

By the property, the above quadratic equation has exactly one positive root.

Its positive root is

$$
Z^{+}=\frac{Y_{2}+\sqrt{Y_{2}^{2}+4 Y_{1} Y_{3}}}{2 Y_{1}} .
$$

We know

$$
I=\frac{1}{\lambda} \ln Z^{+}= \begin{cases}<0, & \text { if } Z^{+}<1, \\ =0, & \text { if } Z^{+}=1, \\ >0, & \text { if } Z^{+}>1,\end{cases}
$$

and $I \in\left[0, I_{\max }\right]$. Therefore, the following rule can be used to select the optimum value of $\mathrm{I}$, for fixed $\mathrm{s}$ and $\tau$ :

$$
I^{*}=\min \left\{I_{\max }, \max \left(0, \frac{1}{\lambda} \ln Z^{+}\right)\right\} .
$$

It is a tedious task to prove the joint concavity of EAP in $\tau, s$, and $I$ because the Hessian matrix is too complex. Therefore, we develop a solution algorithm for finding the optimum solution of the developed model based on the above properties.

\section{Solution Algorithm}

We develop the algorithm based on two concavity properties that we discussed in Section 3. In the algorithm, we consider the selling price " $s$ " as an input variable. For each value of "s," we find the optimal solution by using equations (14) and (20) and applying rule (22). For this purpose, the variable " $s$ " is discretized by taking the initial value as " 0 " and incrementing it by a specific step size in each step within its domain. The solution algorithm is given below.

Solution algorithm:

Step 1: input model parameters $P, a, b, \alpha, \beta, C_{s}$, $C_{h}, C_{u}, I_{\max }, \lambda, \mu_{1}, \mu_{2}, \mu_{3}, \sigma_{1}, \sigma_{2}$, and $\sigma_{3}$ Also, set the value of $z$, the step size of $s$.

Step 2: set $\mathrm{EAP}^{*}=-L$, where $L$ is a large positive number. This, $-L$ is the initial guess of the optimum expected average profit EAP.

Step 3: set $s=0$.

Step 4: calculate $D=\alpha-s \beta$. Also, set green investment $I=0$.

Step 5: solve equation (14) for $\tau$ with most recent values of $s$ and $I$. We can use bisection method to solve this equation taking starting interval as mentioned in Property 1.

Step 6: use equations (20) and (22) to find $I$ with most recent values of $s$ and $\tau$.

Step 7: repeat steps 5 and 6 until $\tau$ and $I$ become stable. It converges very rapidly.

Step 8: calculate the expected average profit (EAP) by equation (8).

If $>\mathrm{EAP}^{*}$, reset $\mathrm{EAP}^{*}=\mathrm{EAP}, s^{*}=s, \tau^{*}=\tau$, and $I^{*}=I$.

Step 9: $s=s+z$ where $z$ is an increment in $s$. For one decimal place accuracy in $s$, the value of $z$ can be taken as 0.1 .

Step 10: if $s<\alpha / \beta$, go to step 4. Else next step.

Step 11: display/print the values of $\operatorname{EAP}^{*}, s^{*}$, $\tau^{*}$, and $I^{*}$.

Step 12: stop.

In the above algorithm, steps 4 to 8 calculate the optimum values of the decision variables $\tau, I$ and, EAP for most recent value of $s$. Step 11 gives the optimum solution of the developed model. 


\section{Implementation of the Proposed Carbon Tax}

Many countries have currently implemented a constant carbon tax system that might be increased or decreased in subsequent years. The constant carbon tax component " $a$ " in this proposed model can be easily implemented according to the existing carbon taxing system adopted by many countries. Every carbon emitter must pay this tax irrespective of whether the emitter is a small firm or a large firm. The second tax component " $b$ " (GE-based) would only be imposed on the large firms. This component represents an additional tax burden for these polluters since they make a significant contribution to climate change. This new carbon tax ensures cleaner production since the firm will try to reduce $G$ by investing in green technology and waste reduction. Ideally, the tax rate " $b$ " should be variant for different industry-based firms since the energy usage and greenhouse gases (GHGs) released by a firm for producing one unit of their product depends on the type of the industry. While estimating the tax rate " $b$ " (in \$) for the firms belonging to a particular industry, we can consider the best performer (with the least $G$ ) among these firms in the previous year as the benchmark. It means that, if the government decides to impose an additional carbon tax of $\$ x$ per unit emission for the best performing firm with the least $G$ in the previous year, then " $b$ " can be taken as $\$(x / G)$. It is mandatory for every firm on which this additional tax is applicable to disclose its annual production and emission data to the regulatory body/government. The second example in the next section provides some ideas about how the government can estimate the tax component " $b$. ."

\section{Numerical Examples}

In this section, we present two numerical examples. The purpose of Example 1 is to validate the model by checking the correctness of the algorithm provided in Section 4. Example 2 demonstrates how the GE-based tax component " $b$ " can be estimated and the impact of the proposed $G E$ based carbon tax on the firms' optimal solutions.

Example 1. We consider five numerical problems by randomly generated model parameters from a specified range for each parameter using uniform distributions. Table 2 displays the ranges of the parameters and their generated values. For the sake of simplicity, except $\lambda$, all generated numbers are rounded to the nearest integers. These problems are solved by using the proposed algorithm, and the results are displayed in Table 3 . In Table 3 , a “*” indicates the value at optimum.

Example 2. In this example, we consider the same five problems as in Example 1 and assume that these problems represent five firms belonging to the same industry sector. They have the same carbon tax structure. To demonstrate the estimation of tax component " $b$," and the impact of the GEbased carbon tax on the firms' optimal solutions, we consider two consecutive years. In the first year, all firms will pay the carbon tax at a constant rate " $a$." Each firm's optimal policy is to maximize its expected average profit (EAP) per year. In the second year, the government will implement the $G E$-based carbon tax to all the firms. At the beginning of the second year, the government will announce the values of the tax components " $a$ " and " $b$ " for the second year to all five firms. Accordingly, the firms will adjust their optimal decisions. We consider the first year's constant carbon tax rate as $\$ 20$ per ton. Using the proposed algorithm, we find the optimal solution of all five firms and presented in Table 4 .

We can observe that the least value of the green index $G^{*}$ is 0.01835 of Firm 1. In the second year, suppose the government wants to impose an additional tax of $\$ 50$ per ton on this bestperforming firm, if it maintains the same $G^{*}$. We set $b G^{*}=50$. This gives, $b=50 / G^{*}=2724.79$, which is rounded to 2725 . The government announces the second year's tax components as $a=20$ and $b=2725$. Now, all the firms recalculate their optimal solutions, presented in Table 5 .

We observe that the green efficiency is improved in the second year due to the imposition of GE-based carbon tax.

\section{Environmental Benefits of GE-Based Carbon Tax}

In this section, we perform two types of analyses to justify the proposed GE-based carbon tax's environmental benefits. First, we perform a comparative analysis between the GEbased carbon tax and the equivalent constant carbon tax on all five problems of Example 1. Here, the equivalent constant carbon tax means the effective carbon tax per unit emission of $G E$-based carbon tax at optimum, i.e., $C_{t}=a+b \times G^{*}$. Second, we consider Example 2 and compare the results between the first year and the second year. Table 6 shows the results of $G E$-based carbon tax and the equivalent constant carbon tax of all five problems.

From these results, the following facts are observed in all five problems.

At optimum, the average emission per unit time $\left(E_{A}{ }^{*}\right)$ is lesser for GE-based carbon tax compared to an equivalent constant carbon tax.

At optimum, the green index $\left(G^{*}\right)$ is lesser for $G E$ based carbon tax compared to an equivalent constant carbon tax.

At optimum, the green investment amount $\left(I^{*}\right)$ is higher for $G E$-based carbon tax compared to an equivalent constant carbon tax.

In the second analysis, we calculate the percentage changes of the $G^{*}, E_{A}{ }^{*}, I^{*}$ and $\mathrm{EAP}^{*}$ due to the imposition of the GE-based tax component in the second year (Example 2). The results are presented in Table 7 .

We can observe in Table 7 that, in the second year, there is a massive percentage reduction in average emissions (column 3) and significant improvement in green efficiency (column 2). Also, there is a considerable increase in green investments (column 4). The percentage reduction in expected average profit for each firm (except Firm 2) is significantly less. Due to an insufficient green budget, Firm 2 could not achieve the actual optimum solution. Without budget restriction, in the 
TABLE 2: Ranges of model parameters and generated parameter values.

\begin{tabular}{|c|c|c|c|c|c|c|}
\hline \multirow{2}{*}{ Parameter } & \multirow{2}{*}{ Range } & \multicolumn{5}{|c|}{ Numerical problems } \\
\hline & & 1 & 2 & 3 & 4 & 5 \\
\hline $\bar{A}$ & $(20,60)$ & 33 & 21 & 50 & 27 & 35 \\
\hline$B$ & $(20,60)$ & 27 & 46 & 41 & 47 & 52 \\
\hline$\alpha$ & $(800,1000)$ & 914 & 895 & 836 & 975 & 969 \\
\hline$\beta$ & $(2,10)$ & 2 & 10 & 2 & 5 & 9 \\
\hline$P$ & $(1000,2000)$ & 1641 & 1752 & 1065 & 1903 & 1962 \\
\hline$C_{s}$ & $(80,120)$ & 88 & 94 & 90 & 113 & 91 \\
\hline$C_{u}$ & $(15,30)$ & 29 & 28 & 18 & 22 & 21 \\
\hline$C_{h}$ & $(1,5)$ & 3 & 2 & 3 & 3 & 1 \\
\hline$\lambda$ & $(0.0001,0.0003)$ & 0.0027 & 0.0003 & 0.0013 & 0.0019 & 0.0008 \\
\hline$I_{\max }$ & $(8000,15000)$ & 11972 & 13402 & 10558 & 8367 & 14265 \\
\hline$\mu_{1}$ & $(30,60)$ & 46 & 33 & 49 & 42 & 30 \\
\hline$\mu_{2}$ & $(30,60)$ & 43 & 31 & 55 & 59 & 39 \\
\hline$\mu_{3}$ & $(30,60)$ & 58 & 42 & 59 & 47 & 38 \\
\hline$\sigma_{1}^{2}$ & $(0,6)$ & 6 & 4 & 6 & 4 & 3 \\
\hline$\sigma_{2}^{\frac{1}{2}}$ & $(0,6)$ & 5 & 3 & 6 & 6 & 2 \\
\hline$\sigma_{3}^{\frac{2}{2}}$ & $(0,6)$ & 1 & 5 & 5 & 2 & 4 \\
\hline
\end{tabular}

TABLE 3: Optimum solutions of numerical problems.

\begin{tabular}{lccccccc}
\hline Example & $\tau^{*}($ year $)$ & $I^{*}(\$)$ & $T^{*}($ year $)$ & $s^{*}(\$)$ & EAP* $\left.^{*} \$\right)$ & $E_{A}^{*}$ (ton) & $G^{*}$ (ton/unit) \\
\hline 1 & 0.6401 & 3157.96 & 2.5042 & 244 & 88958.05 & 4.4748 & 0.01050 \\
2 & 0.0163 & $13402.00^{\&}$ & 5.7115 & 89 & -3396.92 & 10.8133 & 2.1627 \\
3 & 1.5274 & 6924.27 & 4.0871 & 219 & 76566.88 & 3.7073 & 0.00931 \\
4 & 0.6224 & 4258.15 & 2.7869 & 110 & 34267.70 & 6.6331 & 0.01561 \\
5 & 1.5932 & 11696.82 & 8.3356 & 66 & 14049.08 & 4.1478 & 0.01106 \\
\hline
\end{tabular}

${ }^{8}$ Green investment fund is fully utilized. The actual optimum green investment amount is $\$ 27554.66$, which is not achieved due to the green budget restriction.

Table 4: Optimum solutions for the first year.

\begin{tabular}{|c|c|c|c|c|c|c|c|}
\hline \multicolumn{8}{|c|}{ First year } \\
\hline Firm & $a$ & $b$ & $s^{*}$ & $I^{*}$ & $E_{A}^{*}$ & $G^{*}$ & $\mathrm{EAP}^{*}$ \\
\hline 1 & 20 & 0 & 244 & 2936.55 & 7.8173 & 0.01835 & 89036.12 \\
\hline 2 & 20 & 0 & 89 & 0 & 117.8957 & 23.5791 & -2212.83 \\
\hline 3 & 20 & 0 & 219 & 6098.82 & 10.1011 & 0.02538 & 76746.94 \\
\hline 4 & 20 & 0 & 110 & 4041.92 & 9.7194 & 0.02287 & 34330.47 \\
\hline 5 & 20 & 0 & 66 & 10852.38 & 7.8176 & 0.02085 & 14137.32 \\
\hline
\end{tabular}

TABLE 5: Optimum solutions for the second year.

\begin{tabular}{|c|c|c|c|c|c|c|c|}
\hline \multicolumn{8}{|c|}{ Second year } \\
\hline Firm & $a$ & $b$ & $s^{*}$ & $I^{*}$ & $E_{A}^{*}$ & G & $\mathrm{EAP}^{*}$ \\
\hline 1 & 20 & 2725 & 244 & 3360.96 & 2.2762 & 0.00628 & 88931.74 \\
\hline 2 & 20 & 2725 & 89 & $13402.00^{* *}$ & 3.254 & 0.65081 & -14403.51 \\
\hline 3 & 20 & 2725 & 219 & 7091.49 & 3.0226 & 0.00759 & 76592.39 \\
\hline 4 & 20 & 2725 & 110 & 4698.21 & 3.0346 & 0.00714 & 34188.20 \\
\hline 5 & 20 & 2725 & 66 & 12343.18 & 2.5478 & 0.00679 & 14026.40 \\
\hline
\end{tabular}

${ }^{* *}$ Green budget is fully utilized. Insufficient green budget is the reason for a huge loss.

second year, Firm 2 will generate an optimum solution: $G^{*}=0.01252, \quad E_{A}^{*}=3.3167, \quad I^{*}=32307.59, \quad$ and $\mathrm{EAP}^{*}=3688.14$. Therefore, Firm 2 will increase its profit in the second year. We further observe in Tables 3 and 4 that, the optimum selling prices $\left(s^{*}\right)$ are the same in both the years, indicating that no loss of demand after the imposition of GEbased carbon tax. These analyses justify the environmental benefits of the proposed GE-based carbon tax. 
TABLE 6: Comparison of GE-based carbon tax and equivalent constant carbon tax.

\begin{tabular}{lccccccc}
\hline Example & Carbon tax type & Carbon $\operatorname{tax}\left(C_{t}\right)(\$)$ & $s^{*}(\$)$ & $I^{*}(\$)$ & EAP $^{*}(\$)$ & $E_{A}^{*}$ (ton) & $G^{*}$ (ton/unit) \\
\hline \multirow{2}{*}{1} & $G E$-based & $a+b \times G$ & 244 & 3157.96 & 88958.05 & 4.4748 & 0.01050 \\
& Equivalent constant & $a+b \times G^{*}$ & 244 & 3154.354 & 88958.05 & 4.5158 & 0.01060 \\
\hline \multirow{2}{*}{2} & $G E$-based & $a+b \times G$ & 63 & 27554.66 & 3984.42 & 12.6239 & 0.04764 \\
& Equivalent constant & $a+b \times G^{*}$ & 89 & 0 & -2588.98 & 117.8358 & 23.56717 \\
\multirow{2}{*}{3} & GE-based & $a+b \times G$ & 219 & 6924.27 & 76566.88 & 3.7073 & 0.00931 \\
& Equivalent constant & $a+b \times G^{*}$ & 219 & 6917.62 & 76566.89 & 3.7350 & 0.00939 \\
\hline \multirow{2}{*}{4} & GE-based & $a+b \times G$ & 110 & 4258.15 & 34267.70 & 6.6331 & 0.01561 \\
& Equivalent constant & $a+b \times G^{*}$ & 110 & 4242.21 & 34267.77 & 6.8234 & 0.01606 \\
\hline \multirow{2}{*}{5} & GE-based & $a+b \times G$ & 66 & 11696.82 & 14049.08 & 4.1478 & 0.01106 \\
& Equivalent constant & $a+b \times G^{*}$ & 66 & 11673.94 & 14049.11 & 4.21980 & 0.01125 \\
\hline
\end{tabular}

Table 7: Percentage changes in the decision variables in the second year with respect to the first year.

\begin{tabular}{lcccc}
\hline Firm & \% reduction in $G^{*}$ & \% reduction in $E_{A}^{*}$ & \% increase in $I^{*}$ & \% reduction in EAP* \\
\hline 1 & 65.78 & 70.88 & 14.45 & 0.12 \\
$2^{8}$ & 97.24 & 97.24 & NA & 550.91 \\
3 & 70.09 & 70.08 & 16.28 & 0.20 \\
4 & 68.78 & 68.78 & 16.24 & 0.41 \\
5 & 67.43 & 67.41 & 13.74 & 0.78 \\
\hline
\end{tabular}

\&Firm 2's results are quite different from other firms. This happens due to insufficient green budget. Budget is far less than its optimum value.

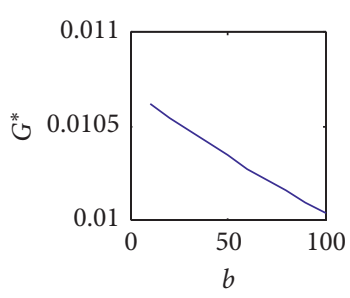

(a)

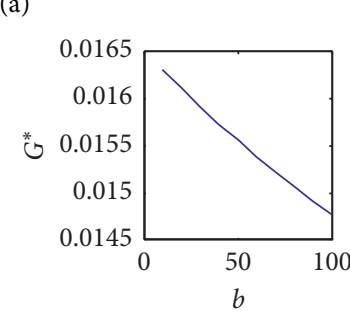

(d)

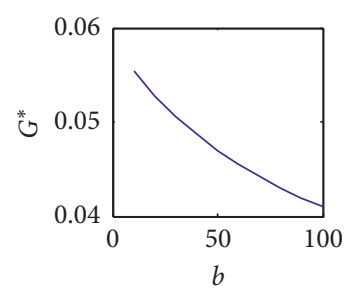

(b)

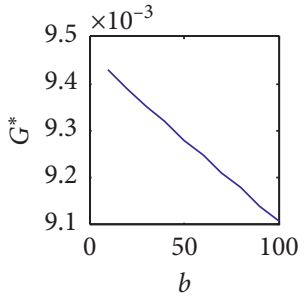

(c)

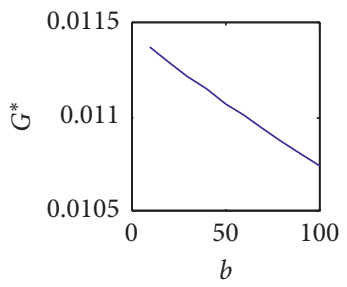

(e)

Figure 1: $b$ versus $G^{*}$ graph. (a) Problem 1. (b) Problem 2. (c) Problem 3. (d) Problem 4. (e) Problem 5.

\section{Effects of the Green-Based Tax Component " $b$ " on the Optimum Solutions}

In this section, we perform an analysis on the five problems defined in Example 1 to observe the effects of the new tax component " $b$ " on the optimum values $G^{*}, E_{A}^{*}$, and $I^{*}$. We take the range of " $b$ " as 10-100 and present the results graphically in Figures 1-3. Figure 1 shows the changes in optimum green efficiency $\left(G^{*}\right)$ for changes in " $b$." Figure 2 shows the changes in optimum average emission $\left(E_{A}^{*}\right)$ for the changes in " $b$." Figure 3 represents the changes in optimum green investment $\left(I^{*}\right)$ for the changes in " $b$."
We observe the following properties from this analysis: $G^{*}$ is strictly decreasing functions of " $b$." This result indicates the better green efficiency for higher " $b$."

$E_{A}{ }^{*}$ is strictly decreasing functions of " $b$." This result shows the lower emissions for higher " $b$."

$I^{*}$ is an increasing function of " $b$." This result indicates that the firm will invest more in green technologies if " $b$ " increases.

These observations further justify the positive environmental benefits of this proposed GE-based carbon tax. 


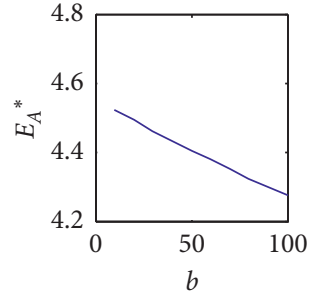

(a)

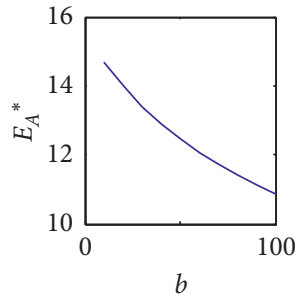

(b)

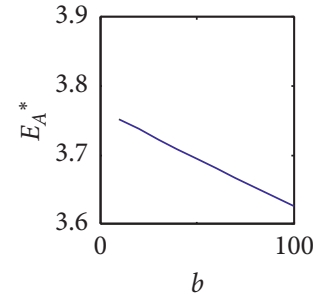

(c)

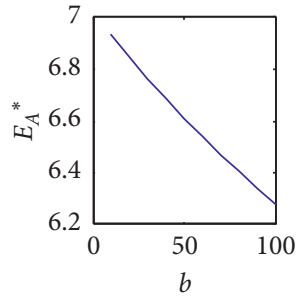

(d)

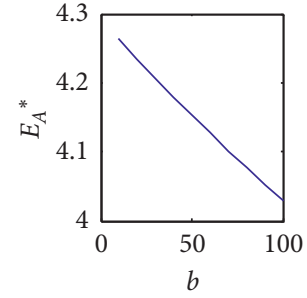

(e)

Figure 2: $b$ versus $E_{A}{ }^{*}$ graph. (a) Problem 1. (b) Problem 2. (c) Problem 3. (d) Problem 4. (e) Problem 5.

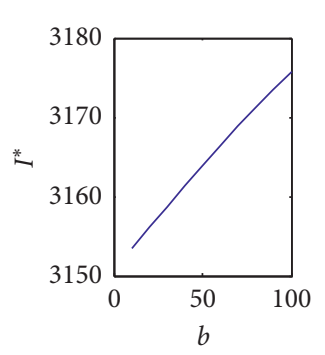

(a)

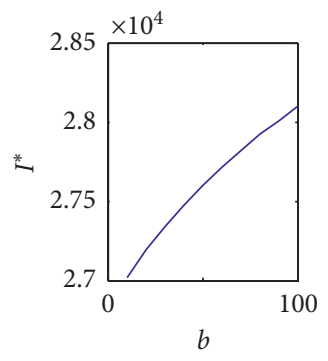

(b)

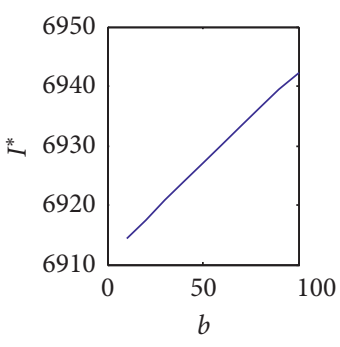

(c)

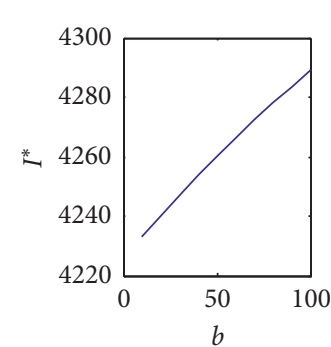

(d)

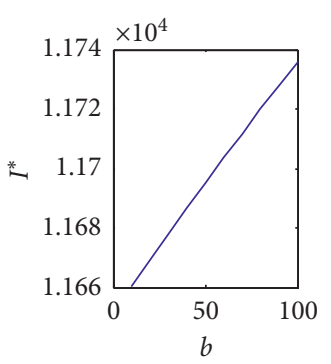

(e)

Figure 3: $b$ versus $I^{*}$ graph. (a) Problem 1. (b) Problem 2. (c) Problem 3. (d) Problem 4. (e) Problem 5.

\section{Concluding Remarks}

A carbon tax is a powerful way to combat carbon emissions. Many countries have enacted a carbon tax to mitigate carbon emissions. This carbon tax is constant and can be modified in subsequent years. In the present study, we propose a novel green efficiency-based carbon taxing policy. This proposed carbon tax has two tax components, a constant tax component and a green efficiency-based tax component. This proposed carbon taxing policy is different from all existing carbon policies. We also suggest how this new tax can be implemented. A solution algorithm is provided. The following are some insights on the proposed GE-based carbon tax derived from this study.

This carbon tax has a very significant positive effect on the environment.

It has almost no effect on annual demand.

It has a less negative effect on the optimal profit. However, in some situations, it can have a positive impact on the optimal profit.
The proposed carbon tax ensures cleaner production and has better environmental benefits than the equivalent constant carbon tax at optimum.

For fixed values of the selling price $(s)$ and green investment $(I)$, the profit function is concave in production run-time $(\tau)$. This property confirms the existence of a unique optimum value of production run-time for every set of values of selling price and green investment amount.

For fixed values of the selling price $(s)$ and production run-time $(\tau)$, the profit function is concave in green investment $(I)$. This property confirms the existence of a unique optimum value of the green investment for every set of selling price and production run-time.

The results of some related models can be derived as special cases of this model. Some of the special cases are mentioned below.

(a) A constant carbon tax model with tax rate " $a$ " can be obtained by substituting $b=0$. This gives, $\tau=$ 
$\sqrt{\left(X_{4} / X_{2}\right)}=\sqrt{\left(2\left(C_{s}+I+a \mu_{1} e^{-\lambda I}\right) D(s)\right) /\left(P(P-D(s))\left(C_{h}+a \mu_{3} e^{-\lambda I}\right)\right)}$, by equation $(14)$ and $I^{*}=(1 / \lambda) \ln \left(Y_{2} / Y_{1}\right)$.

(b) The model with constant carbon tax " $a$ " and without green investment can be obtained by substituting $b=I=0$. In this case, $\tau=$ $\sqrt{\left(2\left(C_{s}+a \mu_{1}\right) D(s)\right) /\left(P(P-D(s))\left(C_{h}+a \mu_{3}\right)\right)}$.

(c) The model with constant demand rate $D$ and without carbon tax can be obtained by substituting $D(s)=D \quad$ and $\quad a=b=I=0$. This gives, $\tau=$ $\sqrt{\left(2 C_{s} D\right) /\left(P(P-D) C_{h}\right)}$, which agrees with the corresponding basic EOQ formula with a finite replenishment rate.

The corresponding cap-and-trade policy model with carbon price $\$ a$ and annual carbon quota $Q$ units can be derived from this developed model by substituting $b=0$ and adding $a Q$ to EAP. One can extend this model by incorporating imperfect products and variable production rates. A hybrid carbon policy model would also be of great interest. This model can also be extended by incorporating inflations.

\section{Data Availability}

No data were used to support this study.

\section{Conflicts of Interest}

The authors declare that they have no conflicts of interest.

\section{References}

[1] T. K. Datta, "Effect of green technology investment on a production-inventory system with carbon tax," Advances in Operations Research, vol. 2017, Article ID 4834839, 12 pages, 2017.

[2] P. D. Williams and M. M. Joshi, "Intensification of winter transatlantic aviation turbulence in response to climate change," Nature Climate Change, vol. 3, no. 7, pp. 644-648, 2013.

[3] J. Tollefson, "IPCC says limiting global warming to $1.5^{\circ} \mathrm{C}$ will require drastic action," Nature, vol. 562, no. 7726, pp. 172-173, 2018.

[4] D. Konur, J. F. Campbell, and S. A. Monfared, "Economic and environmental considerations in a stochastic inventory control model with order splitting under different delivery schedules among suppliers," Omega, vol. 71, pp. 46-65, 2017.

[5] C.-Y. Dye and C.-T. Yang, "Sustainable trade credit and replenishment decisions with credit-linked demand under carbon emission constraints," European Journal of Operational Research, vol. 244, no. 1, pp. 187-200, 2015.

[6] N. Absi, S. Dauzère-Pérès, S. Kedad-Sidhoum, B. Penz, and C. Rapine, "Lot sizing with carbon emission constraints," European Journal of Operational Research, vol. 227, no. 1, pp. 55-61, 2013.

[7] M. C. Arslan and M. Turkay, "EOQ revisited with sustainability considerations," Foundations of Computing and Decision Sciences, vol. 38, no. 4, pp. 223-249, 2013.

[8] S. Benjaafar, Y. Li, and M. Daskin, "Carbon footprint and the management of supply chains: insights from simple models," IEEE Transactions on Automation Science and Engineering, vol. 10, no. 1, pp. 99-116, 2013.
[9] Y. Bouchery, A. Ghaffari, Z. Jemai, and Y. Dallery, "Including sustainability criteria into inventory models," European Journal of Operational Research, vol. 222, no. 2, pp. 229-240, 2012.

[10] X. Chen, S. Benjaafar, and A. Elomri, "The carbon-constrained EOQ," Operations Research Letters, vol. 41, no. 2, pp. 172-179, 2013.

[11] C. H. Glock, M. Y. Jaber, and C. Searcy, "Sustainability strategies in an EPQ model with price-and quality-sensitive demand," The International Journal of Logistics Management, vol. 23, no. 3, pp. 340-359, 2012.

[12] N. Absi, S. Dauzère-Pérès, S. Kedad-Sidhoum, B. Penz, and C. Rapine, "The single-item green lot-sizing problem with fixed carbon emissions," European Journal of Operational Research, vol. 248, no. 3, pp. 849-855, 2016.

[13] M. A. Alhaj, D. Svetinovic, and A. Diabat, "Retracted: a carbon-sensitive two-echelon-inventory supply chain model with stochastic demand," Resources, Conservation and Recycling, vol. 108, pp. 82-87, 2016.

[14] L. Aliabadi, R. Yazdanparast, and M. M. Nasiri, "An inventory model for non-instantaneous deteriorating items with credit period and carbon emission sensitive demand: a signomial geometric programming approach," International Journal of Management Science and Engineering Management, vol. 14, no. 2, pp. 124-136, 2018.

[15] E. Arikan and W. Jammernegg, "The single period inventory model under dual sourcing and product carbon footprint constraint," International Journal of Production Economics, vol. 157, pp. 15-23, 2014.

[16] D. Battini, A. Persona, and F. Sgarbossa, "A sustainable EOQ model: theoretical formulation and applications," International Journal of Production Economics, vol. 149, pp. 145-153, 2014.

[17] E. Bazan, M. Y. Jaber, and A. M. A. El Saadany, "Carbon emissions and energy effects on manufacturing-remanufacturing inventory models," Computers \& Industrial Engineering, vol. 88, pp. 307-316, 2015.

[18] M. S. García-Alvarado, M. Paquet, and A. Chaabane, "On inventory control of product recovery systems subject to environmental mechanisms," International Journal of Production Economics, vol. 165, pp. 132-144, 2015.

[19] P. Gautam and A. Khanna, "An imperfect production inventory model with setup cost reduction and carbon emission for an integrated supply chain," Uncertain Supply Chain Management, vol. 6, pp. 271-286, 2018.

[20] R. Hammami, I. Nouira, and Y. Frein, "Carbon emissions in a multi-echelon production-inventory model with lead time constraints," International Journal of Production Economics, vol. 164, pp. 292-307, 2015.

[21] V. Hovelaque and L. Bironneau, "The carbon-constrained EOQ model with carbon emission dependent demand," International Journal of Production Economics, vol. 164, pp. 285-291, 2015.

[22] P. He, W. Zhang, X. Xu, and Y. Bian, "Production lot-sizing and carbon emissions under cap-and-trade and carbon tax regulations," Journal of Cleaner Production, vol. 103, pp. 241-248, 2015.

[23] T.-Y. Lin and B. R. Sarker, "A pull system inventory model with carbon tax policies and imperfect quality items," Applied Mathematical Modelling, vol. 50, pp. 450-462, 2017.

[24] J. Qin, X. Bai, and L. Xia, "Sustainable trade credit and replenishment policies under the cap-and-trade and carbon tax regulations," Sustainability, vol. 7, no. 12, pp. 16340-16361, 2015. 
[25] Y.-C. Tsao, P.-L. Lee, C.-H. Chen, and Z.-W. Liao, "Sustainable newsvendor models under trade credit," Journal of Cleaner Production, vol. 141, pp. 1478-1491, 2017.

[26] S. Zanoni, L. Mazzoldi, L. E. Zavanella, and M. Y. Jaber, “A joint economic lot size model with price and environmentally sensitive demand," Production \& Manufacturing Research, vol. 2, no. 1, pp. 341-354, 2014.

[27] S. Kundu and T. Chakrabarti, "Impact of carbon emission policies on manufacturing, remanufacturing and collection of used item decisions with price dependent return rate," Opsearch, vol. 55, no. 2, pp. 532-555, 2018.

[28] S. Rani, R. Ali, and A. Agarwal, "Fuzzy inventory model for deteriorating items in a green supply chain with carbon concerned demand," Opsearch, vol. 56, no. 1, pp. 91-122, 2019.

[29] Y. Jiang and D. Klabjan, Optimal Emissions Reduction Investment under Green House Gas Emissions Regulations, Northwestern University, Evanston, IL, USA, Working Paper, 2012.

[30] G. Lou, H. Xia, J. Zhang, and T. Fan, "Investment strategy of emission-reduction technology in a supply Chain," Sustainability, vol. 7, no. 8, pp. 10684-10708, 2015.

[31] A. Toptal, H. Özlü, and D. Konur, "Joint decisions on inventory replenishment and emission reduction investment under different emission regulations," International Journal of Production Research, vol. 52, no. 1, pp. 243-269, 2014.

[32] G. Bi, M. Jin, L. Ling, and F. Yang, "Environmental subsidy and the choice of green technology in the presence of green consumers," Annals of Operations Research, vol. 255, no. 1-2, pp. 547-568, 2017.

[33] Y. Zheng, G. Zhang, and W. Zhang, "A duopoly manufacturers' game model considering green technology investment under a cap-and-trade system," Sustainability, vol. 10, no. 3, p. 705, 2018.

[34] T. K. Datta, P. Nath, and K. Dutta Choudhury, "A hybrid carbon policy inventory model with emission source-based green investments," Opsearch, vol. 57, no. 1, pp. 202-220, 2020. 